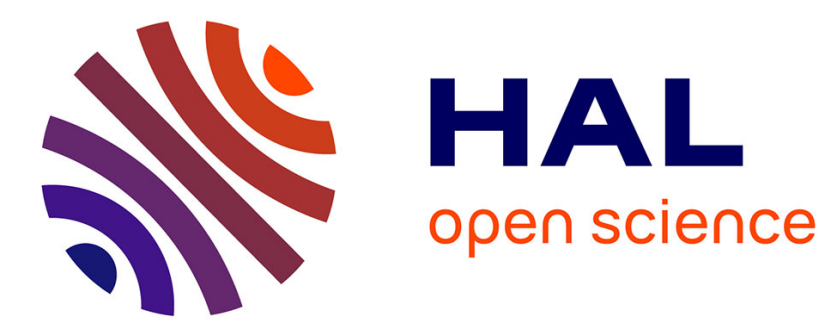

\title{
Online diagnosis of PEMFC by analyzing individual cell voltages
}

\author{
Zhongliang Li, Rachid Outbib, Daniel Hissel, Stefan Giurgea
}

\section{To cite this version:}

Zhongliang Li, Rachid Outbib, Daniel Hissel, Stefan Giurgea. Online diagnosis of PEMFC by analyzing individual cell voltages. 2013 European Control Conference (ECC), Jul 2013, Zurich, France. pp.2439-2444, 10.23919/ECC.2013.6669725 . hal-02476449

\section{HAL Id: hal-02476449 \\ https://hal.science/hal-02476449}

Submitted on 12 Feb 2020

HAL is a multi-disciplinary open access archive for the deposit and dissemination of scientific research documents, whether they are published or not. The documents may come from teaching and research institutions in France or abroad, or from public or private research centers.
L'archive ouverte pluridisciplinaire $\mathbf{H A L}$, est destinée au dépôt et à la diffusion de documents scientifiques de niveau recherche, publiés ou non, émanant des établissements d'enseignement et de recherche français ou étrangers, des laboratoires publics ou privés. 


\title{
Online diagnosis of PEMFC by analyzing individual cell voltages
}

\author{
Zhongliang Li, Rachid Outbib, Daniel Hissel, and Stefan Giurgea
}

\begin{abstract}
Polymer Electrolyte Membrane Fuel Cell (PEMFC) is a promising power source for a wide range of applications. Fault diagnosis, especially online fault diagnosis, is an essential issue to promote the development and widespread use of PEMFC technology. This paper proposes a diagnosis approach for large PEMFC stack. In this approach, flooding fault is concerned, individual cell voltages are chosen as original variables for diagnosis. A dimension reduction method Fisher linear discrimination (FDA) is adopted to extract the features from the cell voltage composed vectors, after that, a classification methodology Gaussian mixture model (GMM) is applied for fault detection. Flooding experiments were conducted on a 20-cell stack to test the approach, the obtained results showed that data points can be classified to different states of health with a high accuracy. It is also verified that the real-time implementation of the algorithm is feasible.
\end{abstract}

\section{INTRODUCTION}

Increasing environment and resource issues draw the more and more attention. Developing an clean and high efficient power generator is urgent in recent years. Fuel cell, as it has lower emissions of $\mathrm{CO}_{2}$, is a promising alternative power generator. In some domains, for instance the transportation applications, PEMFC has been drawing more attention than other types of fuel cell because of its high efficiency, high power density and the ability of operating at low temperatures [1]. However, there are still two barriers: the reliability and durability, which block the wide application of PEMFC.

Fault diagnosis is an efficient solution to overcome the barriers [2]. More particularly, online diagnosis is more effective than offline diagnosis, since it permits an earlier fault diagnosis, more serious faults can be avoided. Additionally, the diagnosis results can be supported to the control unit, thus help adjusting the control commands.

Since the fuel cell system is a nonlinear system, in which the phenomenons of electrochemistry, thermodynamics, and fluid mechanics are coupled together, reliable diagnosis of fuel cell system is a challenge. Some literatures have proposed several fuel cell diagnostic methods. Analytical modeling is an intuitional way to realize the aim of diagnosis [3], however, complicated parameters estimation is needed to get an accurate modeling. In order to overcome the drawbacks of physical model, some "black-box" or "grey-box" models are applied with the aids of some artificial inteligent methods. In

Z. Li and R. Outbib are with the LSIS Laboratory, UMR CNRS 6168, University of Aix-Marseille, 13397 Marseille Cedex 20, France (e-mail: zhongliang.li@1sis.org; rachid.outbib@1sis.org).

D. Hissel is with the University of Franche-Comte (UFC), with FEMTOST/ENISYS (UMR CNRS 6174) and FCLAB, Belfort 90010 Cedex, France (e-mail: daniel.hissel@univ-fcomte.fr).

S. Giurgea is with the University of Technology Belfort-Montbéliard (UTBM) and FCLAB, Belfort 90010 Cedex, France (e-mail: stefan.giurgea@utbm.fr).
[4], authors proposed neural networks model based procedure to diagnose water management faults. A fuzzy diagnostic model is proposed in [5], which is used to diagnose drying of membrane and accumulation of $\mathrm{N}_{2} / \mathrm{H}_{2} \mathrm{O}$ in the anode compartment. Some statistical tools were also developed for diagnosis. In [6], a multivariate statistical method is presented, in which faults can be detected by analyzing principal components. In paper [7], authors proposed an approach based on Bayesian networks, which can handle four types of faults in PEMFC system. In addition, paper [8] introduced a signal analysis approach, in which wavelet package translating methodology is used to detect flooding fault. In [9], authors developed a experimental methodology based on the analysis of the Open Circuit Voltage (OCV) in order to detect leakage faults and locate the fault cells inside the stack.

Although these methods can support us some solutions for diagnosis of fuel cell system, there are still matters need to be improved. Most of the methods consider the fuel cell stack as integration. However, the behaviors of cells are different actually [10], the othernesses of cells should be in consideration. For online diagnosis, the accuracy of fault diagnosis, as well as the implementation cost of the algorithm, which are usually omitted in the literatures, should be evaluated carefully [11].

In this work, we propose an approach for online diagnosis of flooding fault in large PEMFC stack. In the approach, individual cell voltages are analysed by adopting feature extraction and classification methods. Such that data can be classified to normal class, transition state, and fault state. The performance and the feasibility of the approach for online use are evaluated based on the experimental data of a 20cell PEMFC stack.

The rest of the paper is organized as follows: In section 2 , the PEMFC system and the conserned flooding fault are introduced. The details of experiment platform are presented in section 3. In section 4, the diagnosis approach is expounded, including detailed presentations of methodologies: FDA and GMM. The results of diagnosis are given in the next section, the feasibility of online implementation is also discussed in this section. Finally, the conclusion and future work are summarized.

\section{PEMFC SYSTEM AND CONCERNED FAULT}

\section{A. PEMFC system}

An running PEMFC is usually fed continuously with hydrogen on the anode side and air on the cathode side. With the convertion of chemical energy to electric energy, the by-product water is a generated. To produce an useful 
voltage or power, many cells have to be connected in series, which is known as a fuel cell stack. In order to make a fuel cell stack operate in an efficient and safe state, three ancillary circuits, other than fuel cell stack, are usually added to the system: hydrogen circuit, air circuit, and cooling circuit. As Fig. 1 shows, in the hydrogen circuit and air circuit, the flow rates, temperatures, humidities and pressures of gases can be configured or controlled. The temperature of fuel cell stack can be regulated by cooling circuit. The generated water can be taken out by air from the cathode.

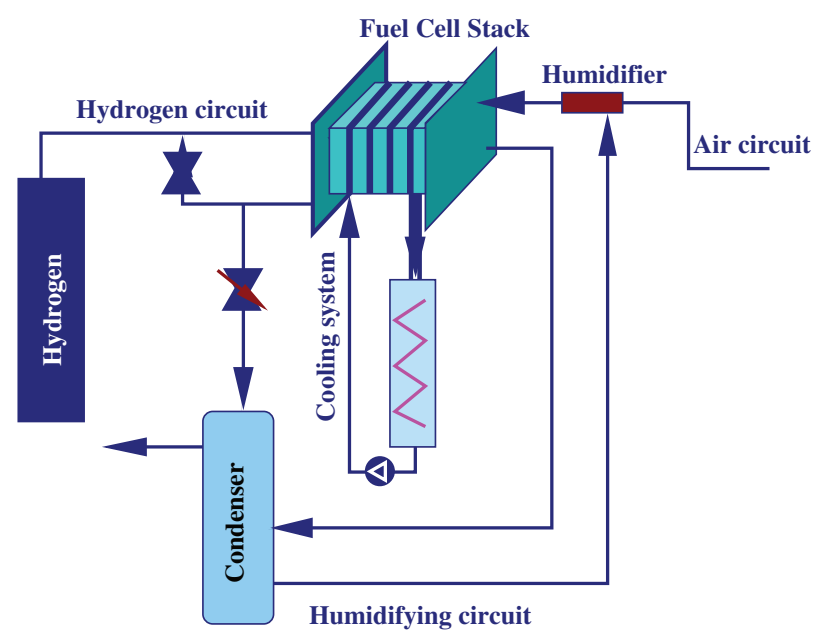

Fig. 1. The schematic of PEMFC stystem [12]

\section{B. Presentation of the concerned fault}

Kinds of faults may occur in the fuel cell system. The faults may happen inside the fuel cell stack or in the ancillary circuits. The faults of ancillary circuits could lead to the faults of fuel cell stack, so that the faults of fuel cell stack can reflect the faults of ancillary components. Additionally, the fuel cell stack is the heart of the whole system. Consequently, the diagnosis of fuel cell stack is prior and cricial. The article will focus on one of the most common faults that occur inside the fuel cell stack: "flooding fault".

As Fig. 2 shows, a typical PEMFC consists of bipolar plates (BPs), gas diffusion layers (GDLs), catalyst layers (CLs), and membrane. On both sides of BPs, gas channels are grooved for gas flow. In a proper functioning PEMFC, the membrane should keep a certain water content to make the protons transport through it effectively with low ohmic resistance. Hence, reactants are humidified before fed into fuel cells. At the same time, the liquid water is generated in the cathode and taken away from fuel cells by air. Inside the fuel cell, water travels among different layers and diffuses between anode and cathode [13]. Some facors, such as gas pressures, gas humidities, gas flow rates, stack temperature, and load current, can impace the balance of the water management. The unbalance of water management may cause the presence and accumulation of liquid water in the gas channels and/or gas porosities of GDLs and CLs, resulting in the flooding fault. Excessive liquid water will block the pathways of reactants, thus make the fuel cell stack degraded. As the water is generated in the cathode side, flooding happens generally in the cathode side.

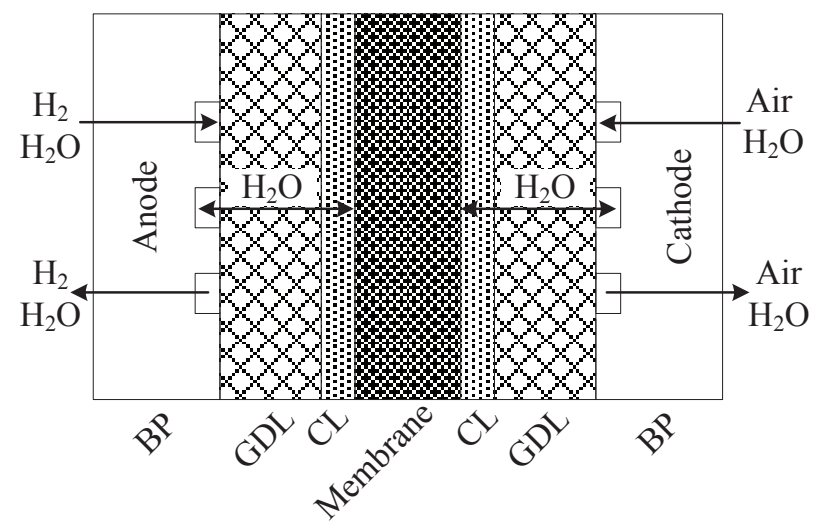

Fig. 2. Schematic picture of water movement inside a PEMFC

\section{EXPERIMENT PLATFORM}

A $1 \mathrm{~kW}$ PEMFC experiment platform is used to test a 20-cell PEMFC stack. Many physical parameters impacting stack performances can be controlled and measured in order to master the operating conditions as specifically as possible. Stack temperature, gas flow rates, fluid hygrometry rates, air dew point temperature and load current can be set. Inlet and outlet flow rates $\left(D_{i}\right.$ and $\left.D_{o}\right)$, pressures $\left(P_{i}\right.$ and $\left.P_{o}\right)$, stack temperatures $\left(T_{s}\right)$, current $(I)$, stack voltage $\left(v_{s}\right)$ and single cell voltages $\left(v_{1}, v_{2}, \ldots, v_{20}\right)$ can be monitored. Table I summarize some parameters of the investigated fuel cell stack.

TABLE I

THE PARAMENTERS OF THE INVESTIGATED FUEL CELL STACK

\begin{tabular}{|c|c|}
\hline Cell area & $100 \mathrm{~cm}^{2}$ \\
\hline Cell number & 20 \\
\hline Nominal output power & $500 \mathrm{~W}$ \\
\hline Nominal operating temperature & $50{ }^{\circ} \mathrm{C}$ \\
\hline Operating temperature region & $20-65^{\circ} \mathrm{C}$ \\
\hline Maximum operating pressures & $1.5 \mathrm{bar}$ \\
\hline Anode stoichiometry & 2 \\
\hline Cathode stoichiometry & 4 \\
\hline
\end{tabular}

\section{THE PROPOSED APPROACH}

\section{A. Selection of variables for diagnosis}

Although in our experimental platform, many physical variables can be collected. The collected variables can be written as a set $\mathcal{T}$

$$
\mathcal{T}=\left\{D_{i}, D_{o}, P_{i}, P_{o}, T_{s}, I, v_{s}, \boldsymbol{v}_{c}\right\}
$$

where $\boldsymbol{v}_{\boldsymbol{c}}=\left\{v_{1}, v_{2}, \ldots, v_{20}\right\}$. However, in practice, in the condition of keeping high diagnosis accuracy, we try to decrease the number of the sensors so as to improve the reliability and lower the cost. Consequently, just a subset of $\mathcal{T}$ is selected as the original variables for diagnosis. 
Individual cell voltages are considered here as the variables for diagnosis for the following reasons:

1) The necessity of monitoring individual cell voltage is stressed. Since the cell with the lowest cell voltage in the stack restricts the maximum power output of the stack [14], fault of a single cell can induce the malfunction of the stack.

2) In general, fuel cell output voltage is highly dependent to the current, electrochemical characteristics, temperature, and aging effect. The fuel cell voltages and their variations contain abundant information that can be used to estimate the parameters of the fuel cell model [15]. In other word, the individual cell voltage can be seen as sensors inside the fuel cell stack.

3) It is observed that appearance of the liquid water change the flow distributions of the gases, and further make the cell voltage distribution varied [10]. So the distribution and relations among the individual cell voltages contain information for diagnosis.

\section{B. The principal of approach}

Pattern classification is an cricial and effcient tool for fault isolation [16]. Classification technique can also be applied for fault detection by adding a class of data which represents the normal state [17]. In this work, a parametric classification methodology GMM is adopted. For large fuel cell stack, the number of fuel cell is large. It means the dimension of data for classification will be high. This will make the classification complicated, and the redundancy of high-dimensional data will lower the accuracy of the classification [18]. In order to overcome these problems, before classification, a dimension reduction method FDA is adopted. The procedure is called feature extraction step. Hence, as Fig. 3 shows, the diagnosis process is composed by three steps: data acquisation, feature extraction and classification. The feature extraction methodologies FDA and GMM classification are reviewed in the following parts.

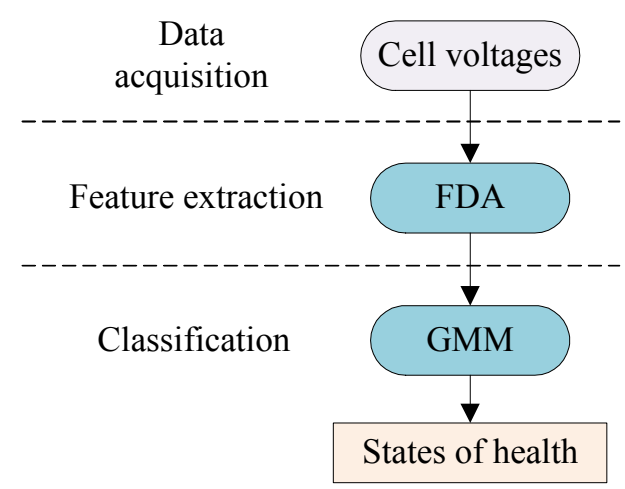

Fig. 3. The flow chart of the proposed diagnosis approach

\section{FDA}

FDA is a technique developed for reducing the dimension of the data in the hope of obtaining a more manageable classification problem. The objective of FDA is to find a mapping vector that makes the data in the same class be projected near to each other while the data in the different classes are separated as far as possible [19], [20].

Given a set of M-dimension objects $\left\{\boldsymbol{x}_{1} ; \boldsymbol{x}_{2} ; \ldots ; \boldsymbol{x}_{N}\right\}$, which belong to $C$ classes denoted as $\zeta_{1}, \zeta_{2}, \ldots, \zeta_{C}$, FDA procedure projects each objects to a L-dimension space by M-dimension unit vectors $\boldsymbol{\omega}_{1}, \boldsymbol{\omega}_{2}, \ldots, \boldsymbol{\omega}_{L}$. Take $\boldsymbol{\omega}_{1}$ as example, vector $\left\{\boldsymbol{x}_{n}\right\}$ is projected to $\left\{y_{n 1}\right\}$

$$
y_{n 1}=\boldsymbol{\omega}_{1}^{T} \boldsymbol{x}_{n}
$$

In order to seek $\boldsymbol{\omega}_{1}$, within-class variance $s_{w}$ is defined in the mapped space

$$
s_{w}=\sum_{i=1}^{C} \sum_{y_{n} \in \zeta_{i}}\left(y_{n}-\bar{y}_{i}\right)\left(y_{n}-\bar{y}_{i}\right)^{T}
$$

where $\bar{y}_{i}$ is the mean value of data in class $\omega_{i}: \bar{y}_{i}=$ $\frac{1}{N_{i}} \sum_{y_{n} \in \zeta_{i}} y_{n} . N_{i}$ is the number of data in $\zeta_{i}$ which satisfies $\sum_{i=1}^{C} N_{i}=N . s_{w}$ represents the variance of the data in the same class.

The between-class variance $s_{b}$ which represents the variance between data in different classes is defined as

$$
s_{b}=\sum_{i=1}^{C} N_{i}\left(\bar{y}_{i}-\bar{y}\right)\left(\bar{y}_{i}-\bar{y}\right)^{T}
$$

where $\bar{y}$ is the mean value of total data: $\bar{y}=\frac{1}{N} \sum_{n=1}^{N} y_{n}$.

We hope to construct a scalar which has the quality that it is large when the between-class covariance is large and within-class covariance is small, one such scalar is given as

$$
J(\boldsymbol{w})=s_{w}^{-1} s_{b}
$$

Substitute $\left\{y_{n}\right\}$ with $\left\{\boldsymbol{w}^{T} \boldsymbol{x}_{n}\right\},(5)$ can be convertered to

$$
J\left(\boldsymbol{\omega}_{1}\right)=\frac{\boldsymbol{\omega}_{1}^{T} \boldsymbol{S}_{b} \boldsymbol{\omega}_{1}}{\boldsymbol{\omega}_{1}^{T} \boldsymbol{S}_{w} \boldsymbol{\omega}_{1}}
$$

where $\boldsymbol{S}_{b}$ named within class scatter matrix is defined as

$$
\boldsymbol{S}_{w}=\sum_{i=1}^{C} \sum_{\boldsymbol{x}_{n} \in \zeta_{i}}\left(\boldsymbol{x}_{n}-\overline{\boldsymbol{x}}_{i}\right)\left(\boldsymbol{x}_{n}-\overline{\boldsymbol{x}}_{i}\right)^{T}
$$

$\overline{\boldsymbol{x}}_{i}$ is mean vector in class $\zeta_{i}: \overline{\boldsymbol{x}}_{i}=\frac{1}{N_{i}} \sum_{\boldsymbol{x}_{n} \in \zeta_{i}} \boldsymbol{x}_{n} . \boldsymbol{S}_{b}$ named between class scatter matrix is defined as

$$
\boldsymbol{S}_{b}=\sum_{i=1}^{C} N_{i}\left(\overline{\boldsymbol{x}}_{i}-\overline{\boldsymbol{x}}\right)\left(\overline{\boldsymbol{x}}_{i}-\overline{\boldsymbol{x}}\right)^{T}
$$

where $\overline{\boldsymbol{x}}$ is the mean vector of total data: $\overline{\boldsymbol{x}}=\frac{1}{N} \sum_{1}^{N} \boldsymbol{x}_{n}$. Both $\boldsymbol{S}_{w}$ and $\boldsymbol{S}_{b}$ are symmetric and positive semidefinite. Usually, $\boldsymbol{S}_{w}$ is nonsingular while $\boldsymbol{S}_{b}$ is singular.

Differentiating (6) with respect to $\boldsymbol{\omega}_{1}$, it is easy to prove that the optimal solution of $\omega_{1}$ is equal to eigenvector of $\boldsymbol{S}_{w}^{-1} \boldsymbol{S}_{b}$ that corresponds to the largest eigenvalue. Consequently, it can be infered that the mapping vectors $\boldsymbol{\omega}_{1}, \boldsymbol{\omega}_{2}, \ldots, \boldsymbol{\omega}_{L}$ are equal to the eigenvectors of $\boldsymbol{S}_{w}^{-1} \boldsymbol{S}_{b}$ that correspond to the first $L$ largest eigenvalues.

Since $S_{b}$ is the sum of $C$ matrixes of rank one or less, only $C-1$ of these are independent, $\boldsymbol{S}_{b}$ is of rank $C-1$ 
or less. Thus, no more than $C-1$ of the eigenvalues are nonzero. The desired mapping vectors correspond to these nonzero eigenvalues. Hence, the maximum of feature space dimension $L$ we can get is $C-1$ [19].

\section{D. $G M M$}

GMM is a parametric clssification methodology based on Bayes decision theory [21]. Bayes' formula is given

$$
p\left(\zeta_{i} \mid \boldsymbol{x}_{n}\right)=\frac{p\left(\boldsymbol{x}_{n} \mid \zeta_{i}\right) p\left(\zeta_{i}\right)}{p\left(\boldsymbol{x}_{n}\right)}
$$

where $p\left(\zeta_{i} \mid \boldsymbol{x}_{n}\right), p\left(\boldsymbol{x}_{n} \mid \zeta_{i}\right)$, and $p\left(\zeta_{i}\right)$ are respectively named as posterier, class-conditional probability, and prior probibility. To decide which class a data point $\boldsymbol{x}_{n}$ belongs to, we should compare the posterier $p\left(\zeta_{i} \mid \boldsymbol{x}_{n}\right)$. It is resolved that $\boldsymbol{x}_{n}$ belongs to the class with the largest posterier. In other words, we just need to compare $p\left(\boldsymbol{x}_{n} \mid \zeta_{i}\right) p\left(\zeta_{i}\right)$ with different $i$. The prior probibility $p\left(\zeta_{i}\right)$ is usually thought to be the frequency weight of data belongs to $\zeta_{i}$, so the main object is to estimate the class-conditional probability density $p\left(\boldsymbol{x}_{n} \mid \zeta_{i}\right)$.

GMM is a efficient probalility distribution model to express the class-conditional probability $p\left(\boldsymbol{x}_{n} \mid \zeta_{i}\right)$. In GMM, class-conditional probability density is represented as a weighted sum of Gaussian component densities.

A Gaussian mixture model is a weighted sum of $R$ component Gaussian densities as the following equation,

$$
p\left(\boldsymbol{x}_{n} \mid \lambda\right)=\sum_{i=1}^{R} p\left(c_{i}\right) p\left(\boldsymbol{x}_{n} \mid c_{i}, \lambda\right)
$$

where $p\left(c_{i}\right), i=1, \ldots, R$ are the mixture weights, which satisfies $\sum_{i=1}^{R} p\left(c_{i}\right)=1, p\left(\boldsymbol{x}_{n} \mid c_{i}, \lambda\right)$ are the component Gaussian densities. Each component density is a M-variate Gaussian function of the form,

$$
\begin{aligned}
p\left(\boldsymbol{x}_{n} \mid c_{i}, \lambda\right)= & \frac{1}{(2 \pi)^{M / 2}\left|\Sigma_{i}\right|^{1 / 2}} \\
& \exp \left\{-\frac{1}{2}\left(\boldsymbol{x}_{n}-\boldsymbol{\mu}_{i}\right)^{T} \Sigma_{i}\left(\boldsymbol{x}_{n}-\boldsymbol{\mu}_{i}\right)\right\}
\end{aligned}
$$

with mean vector $\boldsymbol{\mu}_{i}$ and covariance matrix $\Sigma_{i}$. Parameters $\boldsymbol{\mu}, \Sigma_{i}$ and $p\left(c_{i}\right)$ are collectively represented by the notation $\lambda$,

$$
\lambda=\left\{p\left(c_{i}\right), \boldsymbol{\mu}_{i}, \Sigma_{i}\right\} \quad i=1, \ldots, R .
$$

Before the model training process, the Gaussian component number $R$ is usually settled according to the complexity of the data distribution. In the training process, GMM parameter collection $\lambda$ needs to be estimated from training data. Expectation-Maximization (EM) algorithm is a commonly used method. By iterations, $\lambda$ can be estimated. The details about EM algorithm can be found in [22].

\section{E. Online implementations of the methodologies}

In consideration of the online implementation for FDA, memory space is needed to save $L \times M$ float numbers for mapping vectors $\boldsymbol{\omega}_{1}, \boldsymbol{\omega}_{2}, \ldots, \boldsymbol{\omega}_{L}$. To calculate the features, $L \times M$ times of multiplication operations and $L \times(M-$ 1) times of addition operations are needed to be proceeded for a FDA procedure. Concerning the online implementation for GMM, the parameters of models, including parameter set $\lambda$ and prior probibility need to be saved. Memory for saving $C R\left(\frac{(M+1)(M+2)}{2}\right)+C$ float numbers are required. The $C R\left(M^{2}+M+1\right)+C$ times of multiplication operations and $C R$ times of exponent arithmetic operations need to be carried out for a procedure. It will be shown in the next section that the implementations of the methodologies can be easily realized.

\section{RESULTS AND DISCUSSION}

\section{A. Experiment introduction}

In order to verify our proposed approach, the flooding experiments were carried out. The temperature of stack was decreased from $50{ }^{\circ} \mathrm{C}$ to $35{ }^{\circ} \mathrm{C}$ in order to favor water condensation, while the other experiment conditions were kept in nominal values. To certify the repeatability approach, several independent flooding experiments were carried out. At the end of each test, the load was firstly disconnected from the stack while the air was kept for a length of time. In addition, when we restarted a new experiment, the air circuit was started before adding the load. During the periods, the liquid water inside the fuel cell was cleared away, which certified that there was no flooding occured at the beginning of each experiment.

Various physical variables, denoted as $\mathcal{T}$ in (1), were sampled in the flooding process. The sampling period is $150 \mathrm{~ms}$. Specifically, the cell voltages are analyzed. The cell voltages in one experiment can be presented as a matrix

$$
\mathcal{V}=\left\{\boldsymbol{v}_{1} ; \boldsymbol{v}_{2} ; \ldots ; \boldsymbol{v}_{N}\right\}
$$

where the $n^{\text {th }}$ row vector $\boldsymbol{v}_{n}$ is composed by individual cell voltages

$$
\boldsymbol{v}_{n}=\left\{v_{n}^{1}, v_{n}^{2}, \ldots, v_{n}^{20}\right\}
$$

where numbers $1,2, \ldots, 20$, are index numbers of fuel cells, whose locations are from air inlet side to air outlet side. $n$ is the sequencial number of the sample, the total sample number is $N=6400$. This matrix will be used to train the FDA and GMM models.

\section{B. Results}

Because FDA and GMM are both supervised methodologies. The data for training must be labeled before training procedure. In the flooding course, it is considered that the liquid water accumulates as time. Consequently, the samples are roughly but reasonably labeled that the $1^{\text {th }}$ to the $2500^{t h}$ samples are in normal state, the $2501^{\text {th }}$ to the $3500^{\text {th }}$ samples are in transition state, the $3501^{\text {th }}$ to $6400^{\text {th }}$ samples are in fault state.

The wave forms of cell voltages in a flooding process are as Fig. 4. It can be seen that cell voltages all decrease in the flooding process, however the magnitudes and speeds of the voltage drops are various. Several cells degrade more severely than others. The probable reason for this phenomenon is that, the distributions temperature and air pressure are nonuniform. By comparing the different experiment results, it is found that the degraded extents of a 


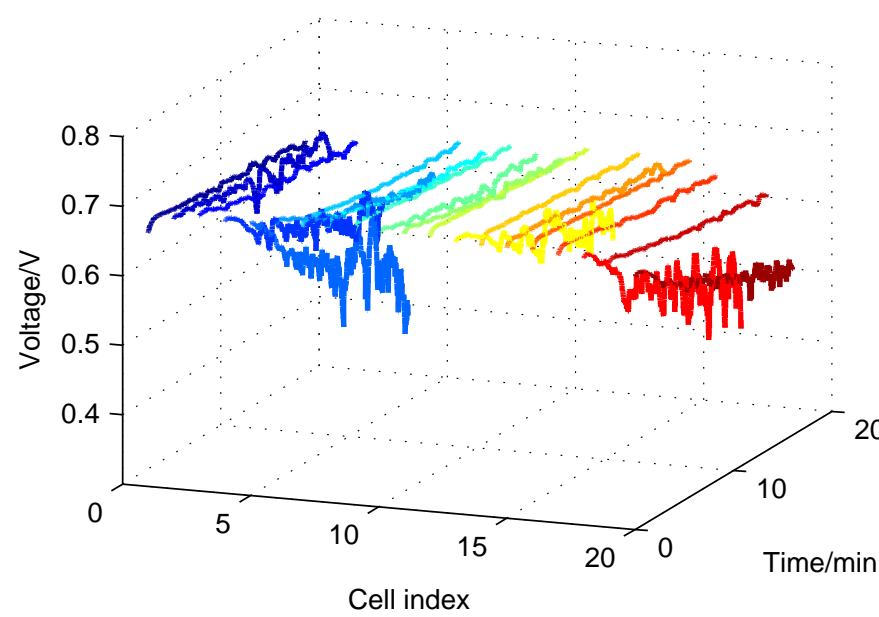

Fig. 4. Cell voltages in flooding process

concerned fuel cell are varied with experiments. In order to slack the impact of the spacial randomness of the flooding occuring. The elements of vectors $\left\{\boldsymbol{v}_{n}\right\}$ are sorted firstly in ascending orders.

After this treatment, the FDA is employed to handle the matrix $\mathcal{V}$. By using FDA, the origninal 20-dimension vectors $\left\{\boldsymbol{v}_{n}\right\}$ are projected to a 2-dimension feature space. The two features are plotted as Fig. 5. It can be observed that

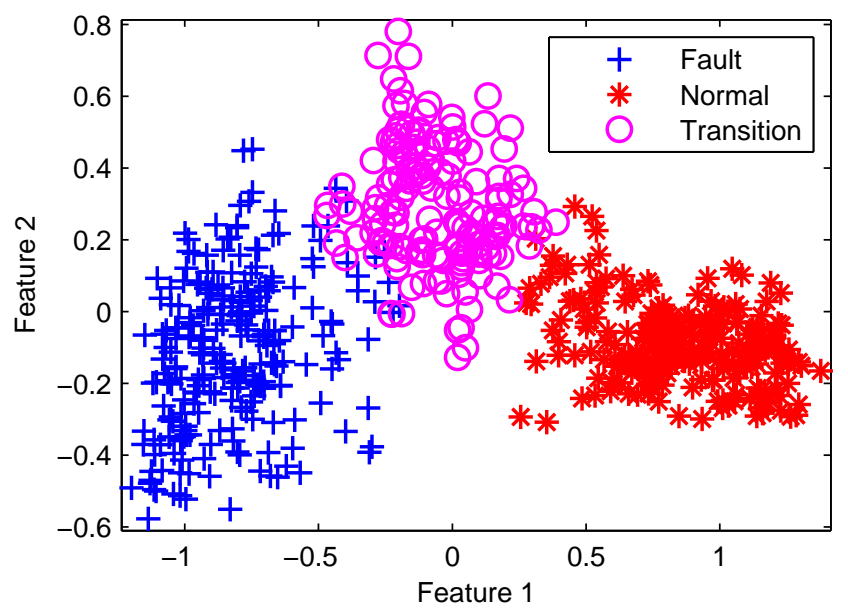

Fig. 5. Features extracted by FDA procedure

data points within each class are gathered, while data points between classes are scattered simultaneously. Just a small overlap occurs between transition class and fault class.

After feature extraction, GMM classification is proceeded in the 2-dimension feature space. Since data points within each class are concentratedly distributed, the number of Gaussian components $R$ is set as 1 . Parameter collection $\lambda$ of each class are estimated by EM algorithm.

After the parameter estimation process, class-conditional probability density of each class is obtained. The prior probibility of each class is set as the frequency weight of data within the class. By multiply class-conditional probability densities with prior probibilities, we can get the posterier of each class. The posteriers of the three classes are plotted as Fig. 6.

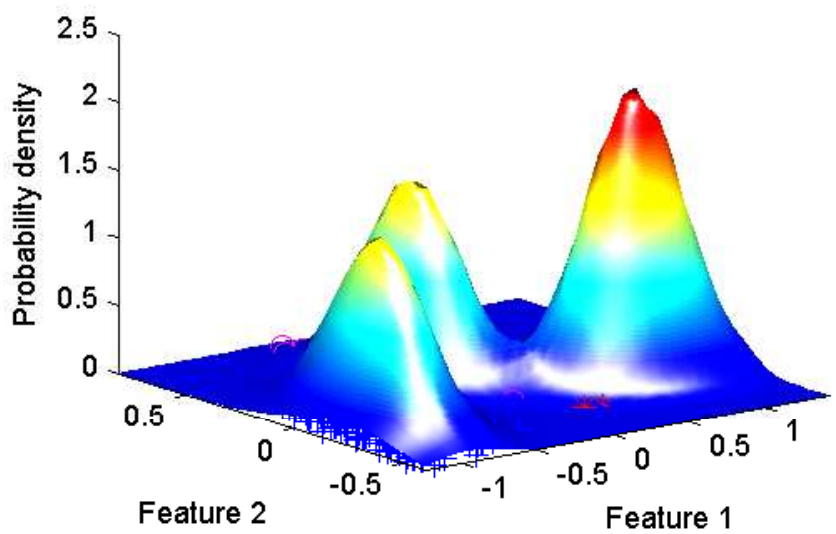

Fig. 6. The posteriors of three classes

By comparing the posteriers of different classes, the twodimension feature space can be divided to 3 zones, which represents respectively normal state, transition state, and fault state. The three zones and boundaries between them are shown as Fig. 7.

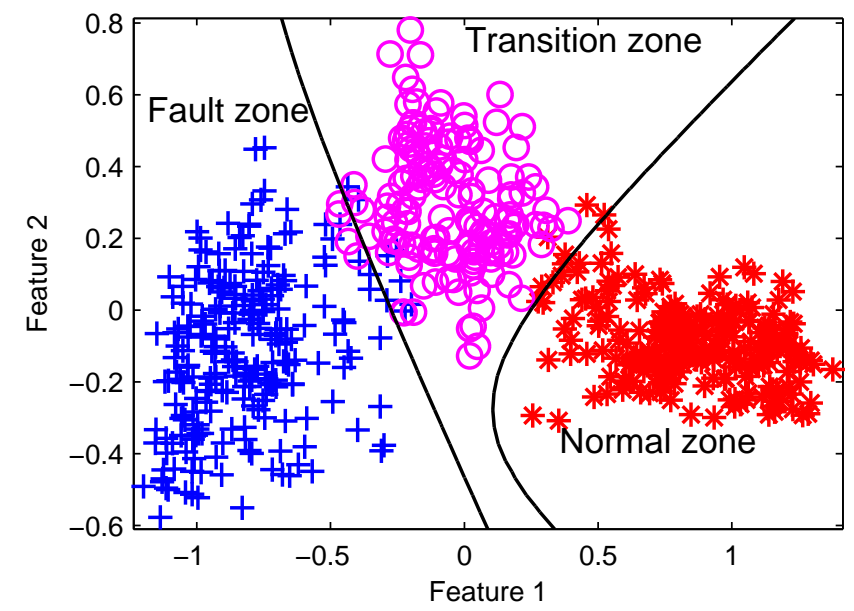

Fig. 7. Partition of three zones in feature space

\section{Discussion}

To evaluate the performance of proposed approach for online application, two aspects are considered: diagnosis accuracy and feasibility of the real-time implementation. 
1) In order to evaluate how accurately it will perform in practice, a popular cross-validation methodology which named K-fold cross-validation is used. In Kfold cross-validation, the total data is randomly divided into $K$ subsets. Of the $K$ subsets, $K-1$ are chosen as training data and rest one subset is used to test the classifier. The error rate, which is defined as proportion of samples that are wrongly classified, is calculated. The training and test process is then repeated $K$ times. The averaged error rate is then obtained to evaluate the classifier. Here, the number of folds $K$ is set to be 10 , after several tests, the average error rates are always less than $3 \%$.

2) According to section 3, to implement our approach, we need to save 736 float number, less than $1.5 \mathrm{k}$ of 16 bit memory are needed. For one diagnosis procedure, 64 times multiplication operations, 38 times addition operations and 3 exponent arithmetic operations. These operations should be done in a sampling period 150 ms. The required memory and computation speed can be satisfied by a common DSP (Digital Signal Processor).

\section{CONCLUSION}

In this paper, a diagnosis approach of large PEMFC stack is proposed. The approach is based on analysis of indivicual cell voltages in flooding process. By adopting feature extraction methodology FDA combined with GMM classification, data points can be classified into three states of health: normal state, transition state, fault state. The error rates of the diagnosis results are low and the software cost of the algorithm can be satisfied easily by a common DSP. It is therefore a suitable approach for online diagnosis.

This study takes into account only the flooding fault, however, the approach can be extended to other fault situations by adding new classes to the training data, such extention is also in process of studying in our laboratory.

\section{REFERENCES}

[1] B. Wahdame, D. Candusso, X. Franc, F. Harel, D. Hissel, and J. M. Kauffmann, "Analysis of a Fuel Cell Durability Test Based on Design of Experiment Approach," IEEE Transaction on Energy Conversion, vol. 23, no. 4, pp. 1093-1104, 2008.

[2] R. Onanena, L. Oukhellou, D. Candusso, F. Harel, D. Hissel, and P. Aknin, "Fuel cells static and dynamic characterizations as tools for the estimation of their ageing time," International Journal of Hydrogen Energy, vol. 33, no. 0, pp. 2-11, 2010.

[3] T. Escobet, D. Feroldi, S. D. Lira, V. Puig, J. Quevedo, J. Riera, and M. Serra, "Model-based fault diagnosis in PEM fuel cell systems," Journal of Power Sources, vol. 192, pp. 216-223, 2009.

[4] N. Yousfi Steiner, D. Hissel, P. Moçotéguy, and D. Candusso, "Diagnosis of polymer electrolyte fuel cells failure modes (flooding \&amp; drying out) by neural networks modeling," International Journal of Hydrogen Energy, vol. 36, no. 4, pp. 3067-3075, Feb. 2011.

[5] D. Hissel, M. C. Péra, and J. M. Kauffmann, "Diagnosis of automotive fuel cell power generators," Journal of Power Sources, vol. 128, pp. 239-246, 2004.

[6] J. Hua, J. Li, M. Ouyang, L. Lu, and L. Xu, "Proton exchange membrane fuel cell system diagnosis based on the multivariate statistical method," International Journal of Hydrogen Energy, pp. 1-10, 2011.

[7] L. Alberto, M. Riascos, M. G. Simoes, and P. E. Miyagi, "On-line fault diagnostic system for proton exchange membrane fuel cells," Journal of Power Sources, vol. 175, pp. 419-429, 2008.
[8] N. Y. Steiner, D. Hissel, P. Moçotéguy, and D. Candusso, "Non intrusive diagnosis of polymer electrolyte fuel cells by wavelet packet transform," International Journal of Hydrogen Energy, vol. 36, no. 1, pp. 740-746, Jan. 2011.

[9] G. Tian, S. Wasterlain, D. Candusso, F. Harel, D. Hissel, and $\mathrm{X}$. François, "Identification of failed cells inside PEMFC stacks in two cases: Anode/cathode crossover and anode/cooling compartment leak," International Journal of Hydrogen Energy, vol. 35, no. 7, pp. 2772-2776, Apr. 2010.

[10] A. Hernandez, D. Hissel, and R. Outbib, "Fuel cell fault diagnosis : A stochastic approach," in Industrial Electronics, 2006 IEEE International Symposium on, 2006, pp. 1984-1989.

[11] I. Samy, I. Postlethwaite, and D. Gu, "Survey and application of sensor fault detection and isolation schemes," Control Engineering Practice, vol. 19, no. 7, pp. 658-674, Mar. 2011.

[12] A. Hernandez, D. Hissel, and R. Outbib, "Modeling and Fault Diagnosis of a Polymer Electrolyte Fuel Cell Using Electrical Equivalent Analysis," IEEE Transaction on Energy Conversion, vol. 25, no. 1, pp. 148-160, 2010.

[13] N. Y. Steiner, P. Moçotéguy, D. Hissel, and D. Candusso, "A review on pem voltage degradation associated with water management: Impacts, influent factors and characterization," Journal of Power Sources, vol. 183, no. 1, pp. $260-274,2008$.

[14] P. Rodatz, F. Büchi, C. Onder, and L. Guzzella, "Operational aspects of a large PEFC stack under practical conditions," Journal of Power Sources, vol. 128, no. 2, pp. 208-217, Apr. 2004.

[15] J. Kim, I. Lee, Y. Tak, and B. Cho, "State-of-health diagnosis based on hamming neural network using output voltage pattern recognition for a PEM fuel cell," International Journal of Hydrogen Energy, vol. 37, no. 5, pp. 4280-4289, Mar. 2012.

[16] R. Isermann, Fault-diagnosis systems-An introduction from fault detection to fault tolerance. Heidelberg, Berlin: Springer, 2006.

[17] S. Yin, S. X. Ding, A. Haghani, H. Hao, and P. Zhang, "A comparison study of basic data-driven fault diagnosis and process monitoring methods on the benchmark Tennessee Eastman process," Journal of Process Control, vol. 22, no. 9, pp. 1567-1581, Oct. 2012.

[18] Z. Zhu and Z. Song, "A novel fault diagnosis system using pattern classification on kernel FDA subspace," Expert Systems With Applications, vol. 38, no. 6, pp. 6895-6905, 2011.

[19] P. E. H. Richard O. Duda and D. G. Stork, Petern Classification, 2nd ed. John Wiley \& Sons, 2001.

[20] C. M. Bishop, Pattern Recognition and Machine Learning. New York: Springer Science \& Business Media, 2006.

[21] J. M. N. Timo Koski, Bayesian Networks: An Introduction, 2nd ed. John Wiley \& Sons, 2009.

[22] G. McLachlan and D. Peel, Finite Mixture Models. New York: John Wiley \& Sons, 2000. 